\title{
Utilization by the growing-finishing pig of wet wheat stored under inter gas atmosphere: Influence of moisture content and grinding fineness
}

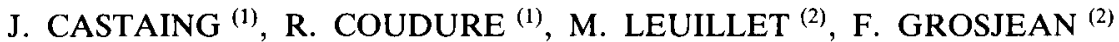 \\ (1) Association Générale des Producteurs de Maïs, 122, boulevard Tourasse, 64000 Pau \\ (2) Institut Technique des Céréales et Fourrages, 8, avenue du Président-Wilson,
} 75116 Paris

Two trials were made in restricted feeding conditions to study the utilization by growingfinishing pigs (between 25 and $103 \mathrm{~kg}$ ) of ground wheat stored in bunker silo under inert gas atmosphere. In each trial, 4 diets were compared : moist wheat $(20$ p. 100 moisture content at harvesting), stored in an inert-gas atmosphere and ground (medium particle size) (diet 1), moist wheat (15 p. 100), stored in an inert-gas atmosphere and medium ground (diet 2) or coarsely ground (diet 3) and finely ground grain wheat stored in micro-silos (diet 4).

In each trial, the weight gain of the animals was not significantly different with the four diets (739-735-729 and $744 \mathrm{~g} / \mathrm{d}$ in the first trial, and 731-724-733 and $737 \mathrm{~g} / \mathrm{d}$ in the second one). The slightly better weight gain observed with diets based on wheat stored as grains in micro-silos may be attributed to the grinding fineness. The carcass quality was not affected by the diet (the muscle percentage was 50.3-50.0-49.9 and 50.3 p. 100 in the first trial and 49.9-50.3-50.5 and 51.5 p. 100 in the second one). The gastro-oesophageal mucosa of pigs fed wheat stored in silos was modified by the fine particle size. This had no effect on the performance.

\section{Influence of the physical form of moist grain maize silage or low oxygen stored grain maize on the performance of bacon pigs}

\section{J. CASTAING ${ }^{(1)}$, R. COUDURE ${ }^{(1)}$, F. GROSJEAN (2)}

(1) Association Générale des Producteurs de Maïs, 122, boulevard Tourasse, 64000 Pau (2) Institut Technique des Céréales et Fourrages, 8, avenue du Président-Wilson, 75116 Paris

Two trials were conducted with diets based on maize supplemented with soyabean meal and minerals and vitamins fed to bacon pigs between 25 and $103 \mathrm{~kg}$ according to a feeding scheme. In both trials, three treatments were compared : a control diet based on dry maize offered as meal at the feeder and a moist maize diet offered either as a meal or as a soup at the trough. In the first trial, moist maize was harvested with $31.5 \mathrm{p} .100$ moisture content and stored ground in bunker silo as silage. In the second trial, moist maize was harvested with 35.7 p. 100 moisture content and stored as grains in tower silo (under inter-gas atmosphere). Grinding was performed every day after unloading.

In the first trial, the daily weight gain was lower with dry maize meal : $698 \mathrm{~g} / \mathrm{d}$ versus 745 and $737 \mathrm{~g} / \mathrm{d}$ with maize silage meal and maize silage soup. The feed conversion ratio was higher with dry maize meal : 3.12 versus 2.94 and 2.97 with maize silages. Muscle percentages were rather similar whatever the diet : $50.8-50.00$ and $51.3 \mathrm{p}$. 100. The gastro-oesophageal mucosa was much more ulcerated with the dry maize diet.

In the second trial, the daily weight gain was lower with dry maize meal : $719 \mathrm{~g} / \mathrm{d}$ versus 743 and 748 and feed conversion ratio was higher : 3.08 versus 2.96 and 2.94 . Muscle percentage was on an average lower with dry maize meal $(49.0 \mathrm{p}$. 100) than with moist maize meal $(50.1 \mathrm{p} .100)$ and with moist maize soup $(51.0 \mathrm{p}$. 100). The gastro-oesophageal mucosa was little affected by the diets. 